\title{
Duration Of Untreated Psychosis And Usage Of Clozapine - 5-years Retrospective Analysis Of First-episode Psychosis In An Inpatient Unit
}

L. Santana1, C. Santos ${ }^{1}$, C. Spínola1 , R. Caetano Silva1,2, J. Gago ${ }^{1,2}$.

${ }^{1}$ centro Hospitalar Lisboa Ocidental, Psychiatry And Mental Health, Lisbon, Portugal.

2universidade Nova De Lisboa, NOVA Medical School - Faculdade De Ciências Médicas, Lisbon, Portugal.

\section{Background}

Duration of untreated psychosis(DUP) is one of the predictors of outcome of schizophrenia. Long DUP as a predictor of poor short-term outcome has been addressed in several metaanalysis and has been systematically shown. To our knowledge, there are no studies addressing the state of the art in Portugal.

\section{Objectives}

To analyze the association between duration of untreated psychosis and usage of clozapine in an Inpatient Unit in Portugal.

\section{Materials and Methods}

Screening of all electronic medical records and charts of patients admitted to the Acute Psychiatric Inpatient Unit of Hospital Egas Moniz in Lisbon, Portugal, between 2013 and 2018.

Semi-structured literature review on duration of untreated psychosis and usage of clozapine was conducterd on Pubmed ${ }^{\mathrm{R}}$ database.

\begin{tabular}{|c|c|}
\hline $\begin{array}{l}\text { Inclusion Criteria }{ }^{1} \\
\text { - } \quad \text { First treatment } \\
\text { contact } \\
\text { - } \quad \text { Age }<50 \text { years }\end{array}$ & $\begin{array}{l}\text { Exclusion criteria }{ }^{1} \\
\text { - } \quad \text { Prior treatment with } \\
\quad \text { antipsychotics }\end{array}$ \\
\hline
\end{tabular}

Results

We found 67 patients meeting criteria.
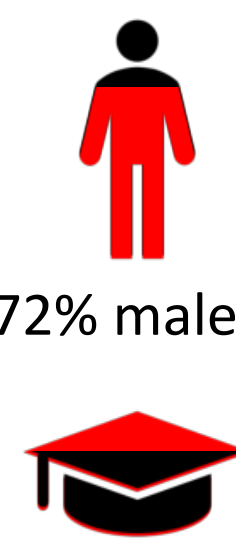

41\% Higher education 29\% Employed
$72 \%$ male

\section{7\% Married} Mean age: $32 \pm 9$ years

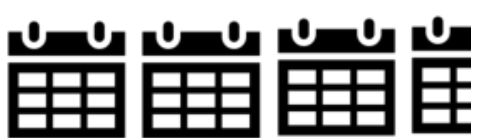

Mean DUP 3,5 months $( \pm 53,33)$

\section{1ै $61 \%$ Compulsory admissions}

\section{Conclusions}

Long DUP is an important prognostic factor that can be modified with populational strategies. This is the first Portuguese study regarding the duration of illness and usage of clozapine, often considered a marker of severity of psychosis at the time of diagnosis.

\section{Key-words: Duration Untreated Psychosis; Clozapine; Schizophrenia; First-episode Psychosis}

\section{References:}

1- Breitborde, N. J., Srihari, V. H., \& Woods, S. W. (2009)

2- Demjaha, A.; Lappin, JM; Patel, MX et al (2017)

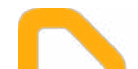

